\title{
INDIVIDUALIZED STUDY SYSTEMS IN THEORY AND PRACTICE
}

\author{
C. F. van der KLAUW and Tj. PLOMP \\ Center for Educational Research and Development, and \\ Department of Applied Mathematics, \\ Technische Hogeschool Twente, Enschede, The Netherlands
}

"There's a suggestion that we have a tiger by the tail!"

F. S. Keller (1971)

\begin{abstract}
After a short characterization of individualized study systems (ISS) and a survey of the number and subject fields of individualized courses in the USA and Europe, the construction and evaluation of an ISSystem in freshman mathematics at the Twente University of Technology is discussed. On the basis of their own experience and data received from others, the authors present a scheme in which the main characteristics of successful ISSystems are outlined.
\end{abstract}

\section{The Development of Individualized Study Systems}

\subsection{WHAT IS AN INDIVIDUALIZED STUDY SYSTEM?}

During the last few years a large number of individualized instructional systems have been developed, particularly in the USA, to adapt instruction to individual differences between students. These systems are based on the following principles.

(a) Mastery learning: A student will in principle arrive at complete mastery of a subject if he spends as much time on it as he needs.

(b) Programmed model: The subject matter is divided into small units (frames) and the student is given feedback on his performance based on tests after every unit. He is only allowed to start on the next unit when he has mastered the preceding one.

(c) Independent use of course-material: The development of technical media (film, t.v., inexpensive copiers) have made instruction independent of the presence of the teacher possible. At all times a student in 
such a system has access to all the course-material (e.g. books, videotapes, diagnostic tests, individual help). The course is well organized and manageable by being divided in separate units (study tasks). For each study task a guide has been written in which are described the task-objectives and the optimal way in which the course-material can be used. As soon as a student considers that he has mastered the subject matter he has the opportunity to confirm this by means of a diagnostic test. If he passes this test he is allowed to start with the next study task. If he fails he gets advice on remedial work. In this way:

- the teaching and learning processes are closely connected to one another;

- individualization is realized because the student can work at his own pace and can often choose from several procedures;

- feedback on achievement becomes possible;

- the role of the teacher changes from information transmission to guidance of learning processes and construction of learning packages. We have called this type of instruction an Individualized Study System (ISS).

\subsection{A SURVEY OF COURSES}

The Universities of Technology at Twente and Eindhoven have been developing individualized courses since 1970. At Eindhoven, there have been a freshman course in Mechanics (Braak et al., 1971) and a course in theories of vibration and the strength of materials (Braak et al., 1972; Verreck, 1973). At Twente, freshmen courses have been constructed in mathematics (differential and integral calculus) and material science (Pilot and Kramers-Pals, 1973).

In the USA the construction of individualized systems began much earlier. Since Keller and Sherman designed an individualized course in general psychology at the Arizona State University in 1965, the development of individualized instructional systems has grown enormously in the USA. Many courses have been constructed in different disciplines under various names, e.g. Personalized System of Instruction (PSI), Self-Paced Study (SPS), Contingency-Management, Modular Instruction, etc. (Goldschmid and Goldschmid, 1974). Keller (1968) was the first to give a systematic outline of the characteristics of this type of instructional system. This outline became known as the "Keller plan." According to Keller these features were: "(1) the go-at-your-own-pace feature which permits a student to move through a course of study at a speed commensurate with his ability and other demands upon his time; (2) the unit-perfection requirement for advance, which lets the student go ahead 
to new material only after demonstrating mastery of that which preceded; (3) the use of lectures and demonstrations as vehicles of motivation, rather than sources of critical information; (4) the related stress upon the written word in teacher-student communication; and finally (5) the use of proctors (student aides), which permits repeated testing, immediate scoring, almost unavoidable tutoring, and a marked enhancement of the personal-social aspect of the educational process."

Scrutiny of the PSI-Newsletter begun by Sherman in 1971 and of publications produced by PSI-Clearinghouses (Hess, 1972; Hess and Sherman, 1972; Hirschi, 1972) shows that over 400 individualized courses are at present being taught in the USA. Table I gives a breakdown of these courses by subject area.

\section{TABLE I}

ISS-Courses in the USA

1. Psychology

2. Engineering; inter alia computer sciences (8), electrical (18), mechanical (6), civil (5), materials/metallurgy (4), chemical (2)

3. Physics and Astronomy: inter alia survey astronomy (2), survey physics (9), introductory physics (14), classical mechanics (5), atomic and nuclear (2), thermodynamics (2)

4. Chemistry: introductory (8), organic (4), physical (3), inorganic (1), biochemistry (2)

5. Biology: survey (3), introductory (2), biochemistry (2) botany (1)

6. Mathematics: survey (4), basic/remedial (11), calculus (9), probability and statistics (2), geometry (1)

. Social sciences: sociology (6), business (2), library science (2)

It is not surprising that many of the individualized courses are in psychology (mostly general or introductory psychology) considering that the instigators of the development of this type of instruction were mainly psychologists (Keller, Sherman and others). The relatively large number of individualized courses in physics, engineering, mathematics and chemistry can be explained in a similar way. B. A. Green, a physicist of the Educational Research Center of the Massachusetts Institute of Technology started a course in physics for 20 freshman in Spring 1969. The success of this course was a sufficient stimulus for Green and his colleagues to construct in that same year two more courses. Courses in quantum physics, organic chemistry and electronics followed (Green 1969, 1971).

A similar development took place at the University of Texas, Austin. 
In Autumn 1969, B. V. Koen gave the first individualized course "Introduction to Nuclear Reactor Theory." Then a number of such courses were developed for the department of engineering: kinematics, dynamics of machinery, digital systems, applied statistics, dynamics of systems, electricity and magnetism. A third institute where a number of individualized courses were given in 1970-1971 was the Worcester Polytechnic Institute in Massachusetts. At least one-third of the undergraduates at this institute are enrolled in an individualized course. One has successfully made use of a multimedia approach incorporating video-tapes.

Outside the USA development of individualized courses has been limited. In Canada, at McGill University in Montreal, about thirty courses have been developed under the name "modular instruction" (see for example, Goldschmid and Goldschmid, 1973). In Europe, as far as we know, there have been only a few individualized courses developed so far. As well as the courses developed in The Netherlands, two individualized courses for small groups have been constructed at the University of Surrey in England: a freshman course in calculus and a course in quantum mechanics for sophomore and junior students (Elton et al., 1972; Boud and Nuttall, 1972). Table II gives a survey of publications on ISS-courses by subject area.

\section{TABLE II}

Publications on ISS-Courses by Subject

1. Psychology: Ferster (1968); Keller (1968); Malott and Svinicki (1969); McMichael and Corey (1969); Shepperd and MacDermot (1970); Born and Herbert (1971); Born Gledhill and Davis (1972); Morris and Kimbrell (1972); Witters and Kent (1972).

2. Engineering: Koen (1970/1971); Braak et al. (1971); Flammer (1971); Hoberock (1971); Koen and Keller (1971); Sears (1971); Braak and Janssen (1972); Hoberock et al. (1972); Verreck (1973).

3. Physics and Astronomy: Green (1969, 1971); Dessler (1972); Philippas and Sommerfeldt (1972); Swartz and Zipfel (1972); Wells (1972): Austin and Gilbert (1973). 4. Chemistry: Shilling (1969); Day and Honk (1970); Conger (1971); Boud and Nuttall (1972); Pilot and Kramers-Pals (1973).

5. Biology: Hurst et al. (1970); Protopapas (1972);

6. Mathematics and Statistics: Myers (1970); Elton et al. (1972); Mattuck (1972); Plomp (1972); Plomp and Van der Klauw (1972, 1973); Wagner and Motazed (1972);

7. Social Sciences: Hoben (1972).

8. Linguistics: Blair (1972).

\subsection{EVALUATION}

In almost all the cases reported, teachers and students were enthusiastic about individualized courses. Students are highly appreciative of 
self-pacing as well as of the opportunity to choose the times at which they are to study. They find too, that the integration of assessment and feedback frees them from the stress of exams.

Kulik et al., (1973) have reviewed the evaluative research on "Keller plan" courses. One of their conclusions is that content learning (as measured by final examinations) is adequate in Keller courses. They find in the published studies that final examination performance in Keller courses always equals, and generally exceeds, performance in lecture sections. Another of their conclusions is that students almost invariably report learning more in individualized than in lecture courses, and that they also nearly always report putting more time and effort into the Keller courses.

Verreck (1973) has confirmed these conclusions. In his course, 30 to 40\% more students finish the course within a semester than in the traditional lecture system, and they reach a higher standard. The students generally judge the course positively and would like other courses to be set up on the same lines.

This does not mean that the introduction of PSI-courses has been without problems, or that there have not been failures. However, Sherman (1972) has analysed a number of unsuccessful courses and concludes that failures were mainly due to deviation from the basic features of the Keller plan, particularly with regard to assessment and to contact between teachers and students. Sherman emphasises the importance of good material in developing a successful course.

An important problem is presented by students who procrastinate. The designers of individualized courses however, are of the opinion that the Keller plan copes to a certain extent with this problem by allowing students to determine their own pace and by providing them with feedback on their progress (feedback which may also serve as an "early warning" system for the instructor). Moreover, increased motivation may be achieved through the differentiation of instructional procedures possible in ISSystems.

\section{An Individualized Study System in Freshman Mathematics}

\subsection{POINTS OF DEPARTURE}

In Autumn 1969 the Department of Applied Mathematics and the Center for Educational Research and Development at the Twente University of Technology decided to design a better instructional system for the freshman course in mathematics. As a result of this co-operation an 
Individualized Study System (ISS) was developed for the course (Plomp and Van der Klauw, 1970, 1972; Plomp, 1972). In the original specification for the new system, the principles of "individualization" and "feedback" were emphasised. The implications of this emphasis for the instructional system were:

(a) Individualization: The student should be able (within limits) to decide when and for how long he studies on a certain part of a course. The subject-matter must therefore be presented in a form which can be used independently by the student. The course should be suitable for a broad spectrum of students. Because of the assumed correlation between certain instructional procedures and certain student types, a variety of instructional procedures should be available.

(b) Systematic feedback: The feedback to the student on his achievement must be related to his progress on the subject-matter rather than to a particular point in time. The instrumentation of the feedback system must be simple. To make it possible for large groups of students to be handled, feedback should be made as automatic as possible.

(c) Courses divided in study tasks: In order to make selective feedback possible and to be able to correct the study process systematically, a division of the course into units (study tasks) is necessary. These tasks will be in partial sequence.

In addition, the following condition was stipulated with regard to the input and pay-off of the system: the system was to be at least as efficient as the present lecture system in terms of student achievement, faculty time and student time, while expenditure on technical aids (e.g. audiovisual aids, computer) was to be kept low.

Two further conditions had to be satisfied because of the requirements of our university:

- the students in the experimental group had to enroll in the lecture system for all their other courses;

- the final examination should consist of open questions on certain predetermined dates. (As a consequence of our experiences with the system, it became clear after some time that this condition could not be fulfilled.)

\subsection{CONSTRUCTION OF THE SYSTEM}

The development of this course is an example of system construction. Starting with the instructional goals, a first version of the course had been constructed on the basis of known educational principles. By means of systematic measurement of the learning and teaching processes and their effects, the system has been improved step by step. The course 
objectives have been formulated, the study tasks determined, the instructional procedures and the testing system designed.

(a) Objectives and study tasks: The method for the formulation of the objectives of the course was simple. The course was based on the textbook Calculus by Ayres (1964). This book contains an extensive collection of problems which can be divided into categories such as knowledge, comprehension and application. It was thus possible to specify the course objectives for each subject. Secondly, the material has been examined for learning hierarchies according to the method developed by Gagné (1970). This analysis provided additional information which helped clarify the objectives. The subject-matter was then divided into six study tasks, each consisting of a coherent entity of concepts, principles and applications. The various tasks are about equal in length. The student can freely choose to start either with task 1 or 2 , and in what order he finishes tasks 3, 5 and 6 ; but he can only finish task 4 when he has finished task 1 as well as 2 . The study tasks are therefore partially in sequence.

(b) Instructional procedures: On the grounds of theoretical principles of curriculum construction and for reasons of efficiency, the following instructional procedures were chosen:

A textbook providing the student with an overview of the theory and giving a number of detailed examples and exercises (Ayres, 1964).

Television lectures, i.e. specially written lectures recorded on videotapes for individual use. These lectures have taken over one of the most important functions of the traditional lectures, the prestructuring of the course material. When we planned these TV lectures we started from the instructions which Gagné (1970) and DeCecco (1968) give for the teaching of concepts, principles and strategies. The $34 \mathrm{TV}$ lectures vary from 15 to 29 minutes, with an average of 22 minutes. In addition to the opportunity to determine himself when he wants to view the video-tapes, the student is also able to rerun all or part of any TV lecture when he so wishes. A written guide has been provided for every TV-lecture containing study notes as well as a few multiple-choice questions to allow the student to check his understanding of the subject-matter. The detailed answers in this guide and reference to the TV lecture make it possible for the student to fill in any gaps quickly and efficiently.

A weekly discussion group was also organized, but there was no obligation for students to take part. These groups were to have the following functions:

- motivation: to interest the students in the subject-matter by posing and discussing problems;

- supporting study planning: the regularity of the discussion groups 
might be expected to encourage some regularity in students' planning of their own work;

- feedback: questions posed by fellow-students help one to discover one's own problems;

- variation: to promote variety in educational procedures.

Under the influence of alterations in the assessment system the function of the discussion groups has changed somewhat over a few years.

There are also weekly consulting hours during which a teacher or a tutor is present to answer questions by individual students.

The total duration of the TV lectures in the ISSystem is 12 $1 / 3$ hours; the total duration of the traditional lectures (about 4 hours a week) on the same subjects is $453 / 4$ hours. In the ISSystem there is a maximum of 2 hours a week for discussion groups; in the lecture system 4 hours a week.

(c) Assessment and feed-back: Initially the final assessment of the mathematics students, i.e. the summative evaluation, took place by means of the usual examination on an appointed date. This was a requirement imposed on the project by the board of the department. The feedback during the course, i.e. the formative evaluation, was given with the help of so-called "diagnostic tests" on the study tasks of the course. The size of these tasks corresponded with the content of three to five TV lectures. The student could take the multiple-choice tests frequently.

It turned out (during 1970-1971) that the students made insufficient use of these diagnostic tests, so that feedback left much to be desired. It was therefore decided during 1971-1972 to incorporate the test scores into the scores on the final assessment with a weight factor. The scores on the tests and on the examination were transformed to a 10-point scale. The scores were included only from those tests on which a student achieved a pass mark; the failures were ignored.

The formula used for the final mark was:

final mark $=$

$3 \times$ mark on examination + marks on passed tests

$3+$ number of passed tests

The tests were adapted to this modified use.

In the second experimental year the feedback by means of the tests did not function adequately either. Therefore from Autumn 1972 it was decided to cancel the usual examination and to assess achievements from test-results exclusively. For every study task a number of parallel achievement tests have been constructed. Furthermore, in each task the student has at his disposal a "practice test," the purpose of which is both to 
provide the student with a means of formative evaluation and to make him familiar with the type of questions in the achievement tests.

These achievement tests are available three to four times a week, and if a student thinks he knows a task well enough he can take a test. If his test-score is up to the standard he can proceed with the next task. If he does not meet the criterion, he receives an advice form with directions for repeating the inadequate parts of the task. If he fails twice for a (parallel) test of a certain task, the causes of the repeated failure are examined in a discussion with the teacher before the student makes a third attempt.

(d) Other characteristics: To make it possible for every student to study in his own way a "study guide" has been written. The topics in the guide are: general information about the system (given at the beginning of the course), the objectives of the course in the form of a survey of the problems, the structure of the tasks, the connection between TV lectures and the textbook, the assessment procedure, the practice tests, and so on.

In order to get prompt feedback and to make it possible to enroll a large number of students in the ISSystem it is necessary to run certain activities automatically. For example, the scoring of the achievement tests is carried out with the help of key transparencies and the study advice is provided by means of advice forms containing a list of prewritten statements. The next step in the development of this course could be computerisation of the scoring and advising.

(e) Realization of the courses: There are $12 \mathrm{TV}$ cubicles in which the students can watch the $34 \mathrm{TV}$ lectures. They are accessible from 8 a.m. until 11 p.m. and during vacations. During the first experimental year (1970-1971) 65 students took part in the course, and there was an additional control group of equivalent size and characteristics which followed traditional instruction. In the second year (1971-1972) 120 students took part in the ISSystem. In 1972-1973, the year in which the development will be concluded, there are 135 students taking part. The ISS-course covers about 50 percent of the first year mathematics in the engineering curriculum.

\subsection{RESULTS}

To research the functioning and pay-off of the system many evaluation questions have had to be posed. Based on the answers the system has been and will be changed during the experimental phase. At the moment the complete results of the first experimental year (1970-1971) are available (see Plomp, 1972). The data concerning 1971-1972 and 19721973 have not all been worked through as yet. 
(a) Student achievement: In the first experimental year the students in the ISSystem got the same results in the mathematics examinations as those in the lecture system (with significantly less time investment by the staff). In the year 1971-1972 there was hardly any difference in test results either. Because of the different design of the testing system this year (1972-1973) better results were expected. This has been confirmed: $74 \%$ of the students have passed the course, compared to only $51 \%$ in the lecture system.

\section{(b) The functioning of the ISSystem}

Textbook: In the ISSystem the students have to study a great part of the material independently using the textbook and the study guide. 90 percent of the students thought such self-directed activity very appropriate. Furthermore, a clear difference emerged between the two instructional systems in the use of the textbook. In the ISSystem the textbook was often used in preparing for the TV lectures and for the discussion groups. In the lecture system the book was not used in preparing for the lectures, and only up to a point in preparing for the discussion groups. It appeared that in the ISSystem self-study from the textbook has taken over part of the task of the discussion groups.

Television-lectures: The TV lectures were used quite frequently, as Table III shows. In both years an average of 30.5 out of 34 lectures was

\section{TABLE III}

Visits to the TV Cubicles

1970-71 1971-72

Total number of visits to the learning carrels

Total number of TV lectures attended Average number of lectures per visit

\begin{tabular}{rr}
863 & 2200 \\
1985 & 3649 \\
2.30 & 1.66 \\
\hline
\end{tabular}

Number of students in experimental groups

followed. The number of visits to the cubicles, however, increased. From a comparison in 1970-1971 between viewing of TV lectures in the ISSystem and attendance at lectures in the traditional system, it appears that the percentage following TV-lectures was considerably higher $(87 \%$ as against $66 \%$ ). It appeared that the students made abundant use of the free choice of time at which the TV lectures could be followed. Given the Dutch setting it is remarkable that the cubicles were visited frequently in the evening. 
One of the facilities offered by the ISSystem is the repetition of all or part of any of the TV lectures. The students used the opportunity for repetition quite frequently ( $54 \%$ of the TV lectures followed). Our records also show that $56 \%$ of the students have seen at least three quarters of the TV lectures. (In another research project of the Center for Educational Research and Development (Van Hout, 1970) only $32 \%$ of the students in a comparable period in 1968-1969 attended more than three-quarters of the lectures in the lecture systems.) A broad range in the duration of the visits to the TV cubicles has also been observed.

Consulting hours: Although the consulting hours were not used frequently they appeared to fill a certain need. Moreover they demanded little time from the teacher in 1970-1971. In later years tutors took over responsibility for consulting hours, as well as for testing.

Discussion groups: The sessions were attended quite frequently. From the evaluation data for 1970/1971 it appears that students consider that the most important function of the discussion groups is to provide hints on how best to study the subject-matter in order to achieve a good result in the examination. As a consequence of the change in the testing system in the year 1972/1973 the function of the discussion groups has also changed. Sometimes it is a consulting session, sometimes the teacher gives an explanation of theoretical topics or problems. In the future the place of group sessions will be examined in the light of course-objectives.

Achievement and feedback: In 1970-1971 feedback using diagnostic tests was not as satisfactory as had been expected. In that year the diagnostic tests and the examination were not linked: the final assessment took place on the basis of an examination which was the same for the experimental group and the remainder of the students. Reward for participation in the tests was only given in the form of advice about gaps in knowledge and comprehension. This appeared to be an insufficient stimulus for a large number of students. The following reasons for not participating in the diagnostic tests (arranged in order of importance) were especially mentioned:

- "They demand extra time, which did not result in any direct advantage to my work."

- "I started late with the preparation of my exam, so I did not have any time left to participate in the tests."

- "The same kind of feedback can be achieved by solving the problems in the textbook."

- "I could not bring myself to do it although I had plenty of time." Therefore in the following experimental year 1971-1972 the results of the tests formed part of the final assessment which was calculated on the basis of the formula mentioned above. Although this year participa- 
tion in the tests was better (especially at the beginning of the course), the feedback system did not function properly. In 1972-1973 the final examination has therefore been cancelled. Grading is based on the achievement tests of the study tasks. This change has given better results in 1972-1973, as we mentioned earlier.

(c) Student satisfaction: The students are more satisfied with the ISSystem than the traditional lecture method used in other courses. They are also more satisfied with their ISSystem than the students who followed traditional mathematical instruction. The following reasons were given for their satisfaction:

- the opportunity to organize and divide one's own time;

- the opportunity to determine for oneself the time when one attends TV lectures, tests, etc.;

- the frequency with which the information is available;

- the minimal extent to which the pace of other students influences one's own pace.

\section{The Basic Scheme of Individualized Study Systems}

On the basis of our experiences with the ISS-course in freshman mathematics and a careful reading of the available literature, we have arrived at the following, tentative conclusions concerning Individualized Study Systems:

Individualization: In order to provide for differences between students, it is important that instruction is available whenever a student wants it, and that he can study at a pace commensurate with his ability and other demands upon his time. This does not mean that he has at his disposal unlimited study time: the course has to be finished within a certain period (e.g. a semester).

Systematic feedback: By means of frequent diagnostic and achievement tests, teacher and student can keep track of progress and identify problems. Testing should take place directly after completion of a study task and the results should be available without delay.

Structured study tasks: The instructional material has to be divided into units (study tasks). In most cases the units conform to the structure of the subject-matter. A unit is primarily concerned with the learning of a number of concepts, principles, formulae and applications of the principles described. This structuring prevents gaps arising in the student's knowledge and comprehension. The extent of the study tasks varies. There are examples of ISS-courses with tasks of one day, but also of a fortnight. It is not always necessary for all study tasks to be worked through in linear order. 
Mastery: A student should master one unit before he proceeds to the next. He is not permitted to move on before mastery has been achieved. The testing procedure should be designed in conformity with this principle.

Independent course-material: An ISSystem can function only when instruction and testing are in a form which can be used independently by the student. In most cases emphasis is laid on printed matter. The teacher writes a study guide describing the study tasks, the objectives for each task, and an overview of the instructional procedures available, such as the textbook, study questions, diagnostic tests, video-tapes, slides, laboratory work, lectures, demonstrations, etc. In many study guides there are also hints on the use of the various procedures. Good directives for the composition of study guides are not available and it is clear that they will have to be brought up-to-date and revised on the basis of regular course evaluation.

Automatization: If intended for use with a large group of students, it is desirable that the administration of the greater part of the system presentation of material, choice of test items, scoring of tests, advising students on progress - is done automatically. Systems differ according to the level of automatisation. In many systems certain procedures are carried out by student aides, e.g. the scoring of tests. In some cases the entire system is administered with the help of a computer.

Modification of teacher tasks: In individualized study systems a change in the teacher's tasks must take place. The teacher is no longer primarily a conveyor of information: this task is taken over by the course-material (book, video-tape, etc.), which he has assembled. His job is to arrange the material, make it accessible, write texts and study guides, etc. While the students study, the teacher evaluates progress, tutors individual students and keeps an eye on the functioning of the whole system. As in the traditional lecture system he has to construct tests (exams), the most important function of which lies not in the formulation of final judgements but in the feedback they provide during the learning process and the possibility they offer of finding out if a student has mastered a study unit to the required standard.

The lectures or discussion groups which sometimes occur in such a system are held for a different purpose. They are used chiefly to motivate students to keep to their study plan, to stimulate social contacts among students (if this is a subgoal of the course), and to enable the group to discuss difficult problems.

As stated above, some of the teaching tasks can be fulfilled by student aides. In many American courses there are students only one year ahead (in study) of their pupils. In view of the comparatively limited task 
assigned to them this is not considered to be a problem. One of the tasks of the teachers is to coach their aides.

The following two points are, in our opinion, not such constraining demands that they have to be built into every ISSystem.

Differentiation in instructional procedures: Individualized Study Systems are meant to take account of individual differences between students. Another way of meeting this demand is to vary instructional procedures. It is on this point in particular that systems may differ substantially. There are some systems in which the instructional procedure consists solely of written material. In others, there are several procedures in use, such as written material, video-tapes, discussion groups, lectures, etc. Different instructional procedures often have the same functions, for instance, transfer of information by means of written material and videotapes. In the ISS-freshman course in mathematics at Twente we have consciously used two forms of presentation side by side in order to allow large groups of students to choose the form which suits them best

Differentiation in study tasks: In ISSystems students may choose between alternative study tasks. This may be desirable, because of the possible differences between students in educational goals. One might envisage study tasks on the same subject, but at different levels. Another possibility would be a number of different options according to students' preferences.

\section{References}

Austin, S. M. and Gilbert, K. E. (1973). "Student Performance in a Keller-Plan Course in Introductory Electricity and Magnetism," Am. J. Phys. 41:12-18;

Ayres, F. (1964). Calculus. New York: McGraw-Hill.

Blair, R. W. (1972). "Experimentation with PSI in the Linguistics Department at Brigham Young University (Utah)." Paper presented at the West Coast PSI Conference, California State University, Long Beach, California.

Born, D. G. (1970a). Instructor Manual for Development of a Personalized Instruction Course. Salt Lake City: Cent. to Improve Learn. and Instruct., Univ. of Utah.

Born, D. G. (1970b). Proctor Manual. Salt Lake City: Cent. to Improve Learn. and Instruct., Univ. of Utah.

Born, D. G. and Herbert, W. A. (1971). "A Further Study of Personalized Instruction in Large University Classes," J. Exp. Educ. 40: 6-11.

Born, D. G., Gledhill, S. M. and Davis, M. L. (1972). "Examination Performance in Lecture-Discussions and Personalized Instruction Courses," J. Appl. Behav. Anal. 5: 33-43.

Boud, D. J. and Nuttall, J. (1972). "Student Examination Performance on Two KellerPlan Courses." Guilford (Eng.): Univ. of Surrey, Inst. Educ. Technol.

Braak, L. H., Esmeyer, W. L., Meuwese, W. A. T. and Tielens, H. J. (1971). Een "Self- 
Paced-Study" systeem (S.P.S.) in de technische mechanica. Eindhoven (Neth.): Technol. Univ., Report WE 71-12.

Braak, L. H. and Janssen, J. D. (1972). De konstruktie en begeleiding van OPA 72. Eindhoven (Neth.): Technol. Univ., Report WE 72-3.

Conger, W. L. (1971). "Mass Transfer Operations - a Self-Paced Course," Chem. Eng. Educ. 5: 122-125.

Day, J. H. and Honk, C. C. (1970). "Student Paced Learning, an Experiment in Teaching Large Classes," J. Chem. Educ. 47: 629-632.

DeCecco, J. P. (1968). The Psychology of Learning and Instruction. Englewood Cliffs, N. J.: Prentice-Hall.

Dessler, A. J. (1971). "Teaching Without Lectures," Rice Univ. Rev. 6.1. (Spring).

Elton, L. R. B., Boud, D. J., Nuttall, J. S. and Stace, B. C. (1972). "An Alternative to the Lecture Course," Guildford (Eng.): Univ. of Surrey, Inst. Educ. Technol. (Interim report).

Ferster, C. B. (1968). "Individualized Instruction in a Large Introductory Psychology Course." Psychol. Rec. 18: 521-532.

Flammer, G. H. (1971). "Learning as the Constant and Time as the Variable," J. Eng. Educ. 61: 511-514.

Gagné, R. M. (1970). The Conditions of Learning (2nd ed.). London: Holt, Rinehart.

$\rightarrow$ Goldschmid, B. and Goldschmid, M. L. (1973). "Modular Instruction in Higher Education: a Review," Higher Educ. 2: 15-32.

Goldschmid, B. and Goldschmid, M. L. (1974). "Individualizing Instruction in Higher Education: A Review," Higher Educ. 3.1.

Green, B. A. (1969). A Self-paced Course in Freshman Physics. Cambridge (Mass.): M.I.T., Educ. Res. Cent., Occ. pap. no. 2.

Green, B. A. (1971). "Physics Teaching by the Keller-Plan at M.I.T.," Am. J. Phys. 39: 764-775.

Hess, J. H. (1972). "A Bibliography of Operant Instructional Technology in Higher Education.” Harrisonburg (Va.): PSI Psychol. Clearinghouse, Eastern Mennonite Coll.

Hess, J. H. and Sherman, J. G. (1972). "PSI Psychology Course Catalog.” Harrisonburg (Va.): PSI Psychol. Clearinghouse, Eastern Mennonite Coll.

Hirschi, S. (1972). "PSI Course Catalog.” Cambridge (Mass.): PSI Clearinghouse, Educ. Res. Cent. M.I.T.

Hoben, G. A. (1972). "An Experimental Adaptation of the Keller Method as Applied in Anthropology 64, Winter 1971." Kalamazoo (Mich.): Dept. of Anthropol., Kalamazoo Coll.

Hoberock, L. L. (1971). "Personalized Instruction in Mechanical Engineering," J. Eng. Educ. 61: 506-507.

Hoberock, L. L., Koen, B.V., Roth, C. H. and Wagner, G. R. (1972) "Theory of PSI Evaluated for Engineering Education," IEEE Tranc. Educ. E15: 25-29.

Hout, J. F. M. J. van (1970). Wiskunde enquête analyse en algebra 1968/1969. Enschede: Twente Univ. Technol. CDO-report nr. 10.

Hurst, R. N., Husband, D. D., Hetkerington, M. T. and Postlethwait, S. N. (1970). “Minicourses as Audio-Tutorial Units," Eng. Educ.: 737-738.

Keller, F. S. (1968). “Goodbye, Teacher ...”, J. Appl. Behav. Anal., 1: 79-89.

Keller, F. S. (1971). "Introduction", PSI-Newsletter $1: 1$.

Klauw, C. F. van der and Plomp, Tj. (1973). "Individuele Studie Systemen," In W. H. van Woerden et al. (eds.), Onderwijs in de maak. Utrecht (Neth.): SpectrumAula. 
Koen, B. V. (1970). "Self-paced Instruction for Engineering Students," Eng. Educ.: $735-736$.

Koen, B. V. (1971). "Self-Paced Instruction in Engineering: A Case Study," IEEE Trans. Educ. E14: 13-20.

Koen, B.V. and Keller, F. S. (1971). "Experiences with a Proctorial System of Instruction," J. Eng. Educ. 61: 504-505.

Kulik, J. A., Kulik, Ch. L. and Carmichael, K. (1973). "The Keller Plan in Science Teaching." Ann Arbor: Cent. for Res. on Learn. and Teach., Univ. of Michigan.

Malott, R. W. and Svinicki, J. G. (1969). "Contingency Management in an Introductory Psychology Course for One Thousand Students," Psychol, Rec. 19: 545-556.

Mattuck, A. P. (1972). "An Exam-Tutorial Program in Calculus at M.I.T.," Comm. Undergrad. Program Math. Newsl. 7: 10-13.

McMichael, J. S. and Corey, J. R. (1969). "Contingency Management in an Introductory Psychology Course Produces Better Learning," J. Appl. Behav. Anal. 2: 7983.

Morris, C. J. and Kimbrell, G. McA. (1972). "Performance and Attitudinal Effects of the Keller Method in an Introductory Psychology Course," Psych. Rec. 22: 523530.

Meyers, W. A. (1970). “Operant Learning Principles Applied to Teaching Introductory Statisties," J. Appl. Behav. Anal. 3: 191-197.

Philippas, M. A. and Sommerfeldt, R. W. (1972). "Lecture Method in General Physics Instruction," Am. J. Phys. 40: 1300-1306.

Pilot, A. and Kramers-Pals, H. (1973). "De konstruktie van een individueel studie systeem materiaalkunde (eerstejaars) aan de T.H. Twente." In W. H. van Woerden et al. (eds.), Onderwijs in de maak. Utrecht (Neth.): Spectrum-Aula.

Plomp, Tj. (1972). ISS-eerstejaars wiskunde: een vooronderzoek. Enschede: Twente Univ. Technol. CDO/TW-report nr. 20.

Plomp, Tj. and Klauw, C. F. van der (1970). Een onderzoek naar individualisering en bestudering van wiskunde onderwijs in de algemene propaedeuse. Enschede: Twente Univ. Technol., CDO-bulletin nr. 3.

Plomp, Tj. and Klauw, C. F. van der (1972). Individueel Studie Systeem voor eerstejaars wiskunde aan de THT. Enschede: Twente Univ. Technol., CDO-bulletin nr. 6.

Plomp, Tj. and Klauw, C. F. van der (1973). "De constructie van een Individueel Studie Systeem (ISS) voor eerstejaarswiskunde." In W. H. van Woerden, et al. (eds.), Onderwijs in de maak. Utrecht (Neth.): Spectrum-Aula.

Protopapas, P. (1972). "Report from a First Time User: after One Year," Pers. Syst. Intr. Newsl. 6: 1-2.

Sears, J. T. (1971). "Developing Intellectual Skiils in a Self-Paced Course," J. Eng. Educ. 61: 515-516.

Sheppard, W. C. and MacDermot, H. G. (1970). "Design and Evaluation of a Programmed Course in Introductory Psychology," J. Appl. Behav. Anal. 3: 5-11.

Shermann, J. G. (ed.) (1971). Personalized System of Instruction Newsletter. Washington, D. C.: Georgetown Univ., Dept. of Psych.

Sherman, J. G. (1972). "PSI: Some Notable Failures," Houston: Keller Method Workshop Conference.

Shilling, G. D. (1969). "A Self-Pacing, Auto-Graded Course," Chem. Eng. Educ. 3: $130-134$.

Swartz, C. E. and Zipfel, C. (1972). "Individualized Instruction in Introductory Physics," Am. J. Phys. 40: 1436-1442. 
Verreck, W. A. (1973). Individualisering in het wetenschappelijk, technisch onderwijs: Evaluatie van een experiment in de technische mechanica. Eindhoven (Neth.): Technol. Univ. (diss.).

Wagner, G. R. W. and Motazed, B. H. (1972). "The Proctorial System of Instruction Combined with Computer Pedagogue for Teaching Statistics," Am. Stat.: 36-39.

Wells, W. C. (1972). "A Personalized System of Instruction in Physics: a Compilation of Keller Plan Resource Materials.” Univ. of Pittsburgh, Dept. of Physics.

Wilson, S. R. and Tosti, D. T. (1972). Learning is Getting Easier: A Guide Book to Individualized Instruction. San Rafael (Calif.): Individual Learning Systems.

Witters, D. R. and Kent, G. W. (1972). "Teaching Without Lecturing: Evidence in the Case for Individualized Instruction," Psychol. Rec. 22: 523-530. 